\section{Thymectomy for Myasthenia Gravis}

SIR,-In your leading article (2 September, p. 543) you discussed the evidence for the existence of a transmissible agent responsible for neonatal myasthenia gravis. Dr. A. D. Korczyn offered an alternative suggestion (30 December, p. 793) implicating anticholinesterase drugs. If the latter were true a higher incidence of neonatal myasthenia would oocur in women taking high doses of medication or for more prolonged periods, or both. This, however, is not the case. Furthermore, several cases of neonatal myasthenia gravis have been reported where the mother was not receiving medication. ${ }^{1}$ In addition, drug requirements decrease in approximately one-third of pregnant women. Other reports provide data that do not support Dr. Korczyn's suggestions. ${ }^{2}$

It has become increasingly evident that thymectomy is followed by improvement and stable remissions in a significant percentage of cases. ${ }^{3}$ Yet no attempt has been made to investigate differences in the incidence of neonatal myasthenia between the prethymectomy and postthymectomy groups. In any such analysis it is important to consider the clinical classification of the disease 4 because: (1) children born to women with ccular myasthenia gravis do not develop neonatal myasthenia; ${ }^{1}$ (2) thymectomy is not generally performed in ocular myasthenia, and therefore this category should be excluded; (3) the severity of the disease (that is, the clinical classification at the peak of symptoms) influence the prognosis both before and after thymectomy; and (4) symptoms during pregnancy are variable and do not necessarily reflect the severity of the disease.

Review of the reported series shows a wide discrepancy in the incidence $(4-50 \%) .1$ Among the lowest ( $4 \%$ ) is the one reported by Fraser $^{5}$ consisting predominately of patients who had undengone thymectomy. A previous report from this institution ${ }^{6}$ reconded 10 out of $69(14 \%)$ cases of neonatal myasthenia. We have now examined the incidence of neonatal myasthenia among 800 myasthenic women (190 postthymectomy). The incidence of neonatal myasthenia gravis in women who had not undergone thymectomy was twice that in the thymectomy group. Our late colleague $\mathrm{Dr}$. K. E. Osserman ${ }^{6}$ indicated that $26 \%$ of pregnancies in myasthenic mothers resulted in spontaneous abortion. Our present review indicates that spontaneous abortions are more common in the non-thymectomy group. Several of the more severe cases of myasthenia, particularly in the nonthymectomy group, had their pregnancies interrupted for medical reasons, and in any comparison of the incidence of neonatal myasthenia these factors must be considered.

Our preliminary data confirm that the variability of the symptoms during pregnancy does not appear to be related to the incidence of neonatal myasthenia gravis. Mothers who gave birth to children with neonatal myasthenia were primarily those in whom the disease reached the more severe forms either before or after the pregnancy. It is obvious that when this factor is taken into consideration the difference is even more pronounced. The effects of thymectomy on myasthenia may be delayed for months or even years. ${ }^{3}$ All cases of neonatal myasthenia in our thymectomy group occurred in women who had not as yet reached complete remission.

These data seem to indicate that the presence of the thymus and possibly a thymic factor play a role in neonatal myasthenia gravis.-We are, etc.,

Angelos E. Papatestas GABRIEL GENKINS

ALLAN E. KARK

Mount Sinai Hospital and School of Medicine, City University,

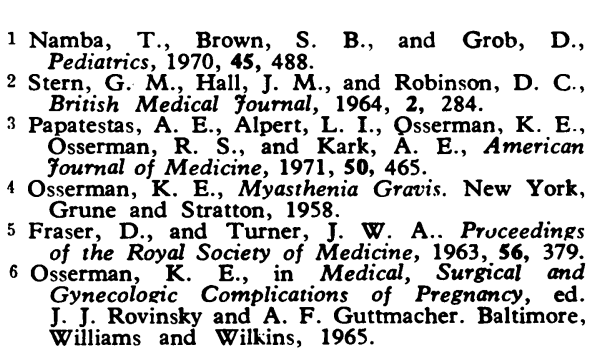

\section{Subclinical Brucellosis}

SIR,-Dr. Eirian Williams (31 March, p. 791) writes that in brucellosis the term "subclinical" "should be used with care." What is meant by this statement? Subclinical is a precise and self-explanatory term to describe a perfectly obvious state. Why then should it be used with care? If Dr. Williams does not recognize subclinical infection or doubts that it exists, then he is simply ignoring the observations of others; the subclinical state in brucellosis is well documented. ${ }^{1-5}$

Further on in his article Dr. Williams admits that in symptomless veterinary surgeons who are continually exposed to brucella antigen all the usual serological tests are positive in high dilution. With the use of what term other than subclinical does he describe their infection?-I am, etc.

Public Health Laboratory,

\section{R. J. HENDERSON} Royal Infirmary,

1 Cayton. H. R.. Osborne. A. D.. and Sylvester,

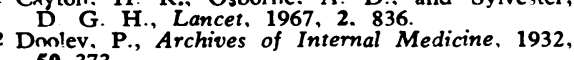

3 Folev, B. V., Clav, M. M., and O'Sullivan, D. I Irish 7ournal of Mediral Scienre, 1970. 3, 457
Frley, B. V.. and O'Flvnn. J. G. A., Irish Ve'erinary fournal. 1971, 25. 42.
Henderson, R. J., Lancet, 1967, 2, 353.

\section{Toxoplasma gondii Oocysts in the Faeces of Naturally Infected Cat}

SIR,-In the course of a general survey of gastrointestinal parasites in domestic animals we found Toxoplasma gondii oocysts in one stray cat (out of 250 examined). Reports about naturally infected cars s.4 $^{-4}$ are extremely rare, and this finding (the first case described in Italv) is reported because of its considerable epidemiological importance to man.

A 4-month-old male stray cat in anparently good health was cantured in the outskirts of Bologna. A dye test (Aagaard's method's) showed a titre of $\angle 1: 10$. His faeces were mushy and dark brown and microsconic examination showed many Isospora felis and T. gondii oocysts after concentration in sodium nitrate and sugar solution (specific gravity 1300). $T$. gondii oocysts kept in $2.5 \%$ potassium dichromate sporulated after 16 days. The sporulated oocysts were washed in saline in a centrifuge and injected intraperitoncally into 5 dye-test-negative mice $(-1: 10)$. Oocysts were also given orally to two cats (2-month-old), onc of them (cat A) showing a dye test titre of $<1: 10$ and the other (cat B) of $1: 50$.

After four wecks all the inoculated mice had dyc test of $>1: 250$ and the microscopic cxamination of their brains showed typical toxoplasma cysts. The faeces from cat $\mathbf{A}$ were negative for $T$. gondii throughout the whole observation period (45 days) but a dye test on the 16 th day reached $1: 250$. This fell to $1: 50$ on the 26th day and remained unchanged. On the third day occasional sporulated oocysts were found in the faeces of cat $B$, these apparently representing a transit of the ingested noculum. The facces became negative on the following day. On the 27th day new, abundant and unsporulated $T$. gondii oocysts appeared. They pะrsisted for threc days. Later, however, the farces remaincd ncgative. The original dyctest titrc of $1: 50$ reached $>1: 1,250$ on the 16 th day and remained so till the animal was killed (45th day). $T$. gondii cysts were isolated in mice injected with brain material from cat $B$.

These data confirm that cats may be responsible for the natural spread of $T$. gondii ocysts. The oocyst displays its infectivity after some days at sporont maturation (16 days in the present case) but sometimes seems to be already infective at emission (transit oocysts from contaminated food). The marked rise of the dye test titre associated with emission of oocysts in cat B (already positive before the experimental infection) seems to show that cats who have previously had $T$. gondii infection may become spreaders again by a renewed oral load of parasites. The results of the dye test in cats excreting $T$. gondii oocysts do not seem to represent a reliable indication for epidemiological investigations on cats, because their range may vary from comparatively high values (cat B) down to nothing (naturally infected stray cat).-We are, etc.,

S. Pampiglione G. POGLAYEN B. ARNONE

Cattedra di Parassitologia, Università di Bologna, Italy

Instituto di Malattie Infettive, Università di Milano

Centro Studi sulla Toxoplasmosi,

1 Jacobs, L., in Advances in Parasitology, vol. 5, ed. B. Dawes. London, Academic Press, 1967. Wallace, G. D.,

1971, 124, 227. and Kühn D Berliner and Münchener Tierärztliche Wochenschrift, 1972,
Mün, $85,46$.

4 Wermer, J. K.. Wand Walton, B. C., fournal of Berengo, A., de Lalla, F., Bechelli, G., and Cavallini-Sampiers, L., Minerva Medica, 1969,
60, 377 .

\section{Smoking and Ischaemic Heart Disease}

SIR,-It is stated in the interesting paper by Dr. Nicholas Wald and others (31 March, p. 761) that "there is a well recognized correlation between smoking and atherosclerosis." The data cited in support show, however, that there is an association between smoking and clinical ischaemic heart disease. It is at least possible that these are not two identical propositions.

It is true that death from myocardial ischaemia is unlikely in the absence of coronary atheroma but, as Morris ${ }^{1}$ has said, many are susceptible to the latter but far 